\title{
Comparative outcomes of radio frequency ablation versus partial nephrectomy for T1 renal tumors: a systematic review
}

\author{
Xiyi Wei ${ }^{1,2 \#}$, Xiaohan Ren ${ }^{2 \#}$, Yichao Ding ${ }^{3 \#}$, Hongye Wang ${ }^{2}$, Yunxin $\mathrm{Li}^{2}$, Xiao $\mathrm{Li}^{1}$, Yang Gao ${ }^{4}$ \\ ${ }^{1}$ Department of Urology, Jiangsu Cancer Hospital \& Jiangsu Institute of Cancer Research \& Affiliated Cancer Hospital of Nanjing Medical \\ University, Nanjing 210009, China; ${ }^{2}$ First Clinical Medical College of Nanjing Medical University, Nanjing 210029, China; ${ }^{3}$ School of Nursing of \\ Nanjing Medical University, Nanjing 210029, China; ${ }^{4}$ Department of Radiology, Jiangsu Cancer Hospital \& Jiangsu Institute of Cancer Research \& \\ Affiliated Cancer Hospital of Nanjing Medical University, Nanjing 210009, China \\ Contributions: (I) Conception and design: X Wei, Y Gao, X Li; (II) Administrative support: None; (III) Provision of study material or patients: None; \\ (IV) Collection and assembly of data: X Wei, X Ren, Y Ding, Y Li, H Wang; (V) Data analysis and interpretation: X Wei, X Ren, Y Ding; (VI) \\ Manuscript writing: All authors; (VII) Final approval of manuscript: All authors. \\ "These authors contributed equally to this work. \\ Correspondence to: Xiao Li. Department of Urology, Jiangsu Cancer Hospital \& Jiangsu Institute of Cancer Research \& Affiliated Cancer \\ Hospital of Nanjing Medical University, Nanjing 210009, China. Email: leex91@163.com; Yang Gao. Department of Radiology, Jiangsu \\ Cancer Hospital \& Jiangsu Institute of Cancer Research \& Affiliated Cancer Hospital of Nanjing Medical University, Nanjing 210009, China. \\ Email: gaoxinran1989@163.com.
}

Background: The role of radio frequency ablation (RFA) in small renal tumors remains controversial. This
systematic review was performed to compare clinical outcomes of RFA versus partial nephrectomy (PN) for
the treatment of T1 renal tumors.
Methods: A total of 11 studies including 2,397 patients were analyzed in this systematic review after
searching the databases of PubMed, EMBASE and Web of Science. P value and odds ratio (OR)/hazard ratio
(HR) with 95\% confidence interval (CI) were used to evaluate the strength of the association.
Results: A total of six studies ( 2,056 patients) provided either survival curves or HR and its $95 \%$ CI,
demonstrating that the majority of the patients with RFA treatment tended to exhibit a similar long-term
survival rate to those with PN treatment. In addition, according to four studies, no differences were found
in the overall rate of complications between the two groups. Furthermore, there were significant differences
in glomerular filtration rate (GFR) change between the two methods in four studies but no differences were
observed in other two.

Conclusions: Our systematic review indicated that RFA is an effective treatment option which could provide comparable oncologic outcomes to PN. Moreover, it may present obvious advantages in renal function preservation.

Keywords: Radio frequency ablation (RFA); partial nephrectomy (PN); T1 renal tumors; systematic review

Submitted Jun 21, 2019. Accepted for publication Sep 29, 2019.

doi: $10.21037 /$ tau.2019.10.13

View this article at: http://dx.doi.org/10.21037/tau.2019.10.13

\section{Introduction}

Renal cell carcinoma (RCC), accounting for approximately $2-3 \%$ of all malignancies in adults, is considered as the seventh most common cancer in male and the ninth most common cancer in female (1). There are approximately 209,000 new cases and 102,000 deaths reported each year worldwide (2). Recently, the detection rate of RCC has grown with the increasing use of cross-sectional imaging, resulting in a great number of accidentally diagnosed small RCCs with lower histological grades and lower possibility of metastases (3-6).

Traditional surgical treatment of renal tumors has 


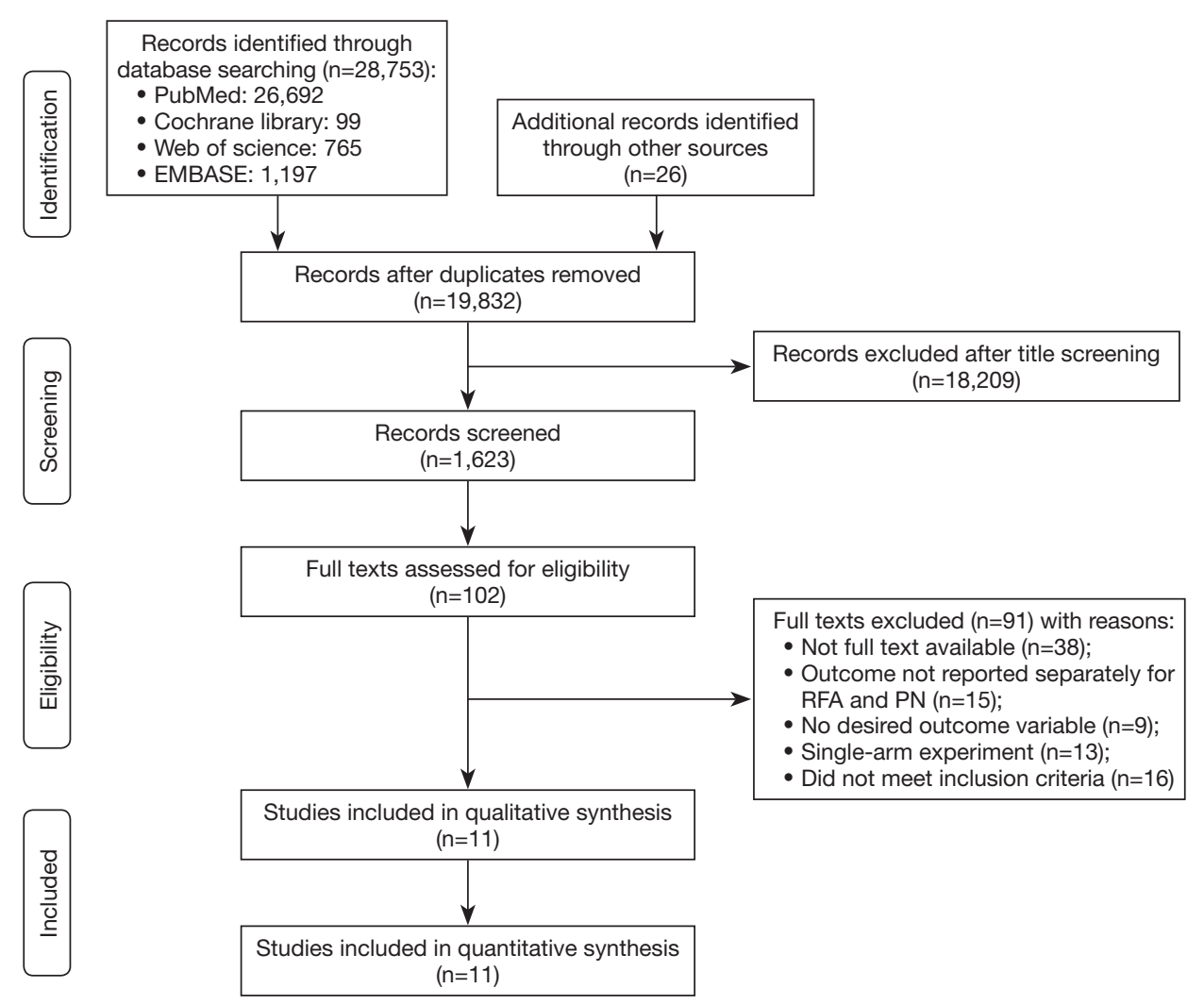

Figure 1 Flow diagram of the study selection process.

undergone a transformation in the past decade (7). Previously, partial nephrectomy (PN) was shown as a common surgical procedure for the treatment of $\mathrm{T} 1$ renal tumors $(8,9)$. But in recent years, novel minimally invasive procedures [e.g., radio frequency ablation (RFA)] have been increasingly applied (10). The principle of RFA is to destroy the tumor tissues with heat and desiccation by radio frequency current, which can be performed through open incisions, laparoscopic or percutaneous routes under image guidance [i.e., ultrasound (US), magnetic resonance imaging (MRI), computed tomography (CT)] (11-13).

However, elderly patients with T1a stage (defined as a tumor $4 \mathrm{~cm}$ or less, confined to the kidney) or patients who cannot undergo a surgery are more appropriate for minimally invasive surgery of RFA to avoid unnecessary surgical complications (14). Furthermore, high temperature of RFA may bring about some side effects, such as inadvertent injury of non-target tissues. In consequence, the efficacy and safety of RFA in the treatment of T1 renal tumors remain controversial. Therefore, we performed a systematic review to compare outcomes (include long- term survival rates, complication events and renal function changes) of RFA versus PN in the treatment of T1 renal tumors.

This systematic review followed the PRISMA guidelines (15).

\section{Methods}

\section{Search strategy}

Several electronic databases were searched to identify relevant literature including PubMed, EMBASE and Web of Science with a deadline of March 30, 2019. Basically, only studies published in English were included in this systematic review. For the literature retrieval, the following key words were utilized: ("percutaneous ablation", or "radio frequency ablation"), ("partial nephrectomy", or "nephrectomy"), and ("T1 renal cell carcinoma", "T1 renal tumor", or "T1 renal masses"). In order to minimize the omission of the study, we manually screened the list of references for eligible studies to obtain more publications. A flow diagram of the study selection process is presented in Figure 1. 


\section{Inclusion and exclusion criteria}

Eligible studies should meet the following criteria: (I) studies comparing the outcomes between RFA and PN in T1 renal tumors; (II) data obtained in different studies did not overlap. Instead, the exclusion criteria were displayed as follows: (I) studies consisted no usable data of outcomes of RFA versus $\mathrm{PN}$ in the treatment of T1 renal tumors; (II) studies had overlapped data; (III) reviews, abstracts or animal studies.

\section{Data extraction}

All useful data involved in eligible studies were extracted by two investigators (X Wei and X Ren) independently. The results were reviewed by a third investigator (Y Ding). The following elements were extracted from each selected study: (I) name of first author, publication year, study design, type of RFA and PN; (II) number of patients (case and control), follow-up period; (III) basic information of total patients; (IV) survival curves or hazard ratio (HR) and its $95 \%$ confidence interval (CI); (V) treatment complications; (VI) renal function changes.

\section{Quality assessment}

Newcastle-Ottawa Scale (NOS) was used to evaluate the quality of articles included. All 11 studies were evaluated strictly and scored at least 7 points (Table 1).

\section{Results}

\section{Characteristics of included studies}

A total of 11 relevant studies (16-26) were finally included in this systematic review, including 2,397 patients with the average age of 59.07. The characteristics of patients receiving RFA or PN treatment are displayed in Table 1. The summary results indicated that most patients in the RFA group were visibly older $(16,18,21,22,24)$. Five studies showed smaller tumor size in RFA group than those in the PN group (16,18,20-22), while two studies show larger tumor size $(23,25)$. However, no statistical differences were observed in gender (16,17,19,21-25).

\section{Long-term survival rates}

A total of 6 studies (1,700 patients) provided either survival curves or HR and its 95\% CI. As indicated in Table 2, the HR of overall survival for RFA compared with PN were provided in three articles [Chang 2015: $\mathrm{HR}=1.00$ (0.81-1.24); Chang 2015: HR =0.86 (0.49-1.50); Thompson 2015: HR $=1.99(1.62-2.45)]$. The results from Chang et al. and Chang et al. $(20,21)$ showed no significant survival advantage for RFA, while the advantage of PN could be observed in Thompson's research (22). In addition, three studies consistently exhibited insignificant differences in recurrence-free survival time [Chang 2015: HR $=1.02$ (0.67-1.56); Sung 2012: HR =1.06 (0.84-1.31); Stern 2007: $\mathrm{HR}=1.08(0.53-2.22)]$.

\section{Overall complication events}

Six studies (559 patients) reported the overall complication events, including urine leak, urinary retention and delay bleeding. Complications were classified by the ClavienDindo classification system. As is displayed in Table 3, a total of 48 complication events were observed, in which minor complications accounted for more than $80 \%$ of all complications. According to four studies $(19,21,24,25)$, there were no obviously differences in the incidence of total complications between two groups $(\mathrm{P}=1, \mathrm{P}=0.241, \mathrm{P}=1$, and $\mathrm{P}=0.47)$.

\section{Pre/post-GFR and GFR change}

Nine studies (1,083 patients) provided either pre/postGFR or change in GFR. Detailed differences in pre/postGFR between the two group are summarized in Table 4. According to the results from Zhu et al. (17), Pantelidou et al. (18), Huang et al. (19) and Sung et al. (24), the decline in GFR was smaller in the RFA group than in the PN group $(\mathrm{P}<0.001, \mathrm{P}<0.0001, \mathrm{P}=0.048, \mathrm{P}=0.013$, respectively). However, no significant differences were found in studies of Park et al. (16), Cooper et al. (23) and Takaki et al. (25) $(\mathrm{P}=0.395, \mathrm{P}=0.8959, \mathrm{P}=0.34$, respectively).

\section{Discussion}

With the advancement of nephron-sparing technology, traditional surgical procedures have been challenged by new minimally invasive ablation, such as RFA, microwave ablation and cryoablation $(27,28)$. Several previously published studies have demonstrated that RFA was an alternative treatment for T1 RCC with acceptable midterm results and lower risk of complications (29). Nonetheless, there were still several studies revealing that RFA had the 


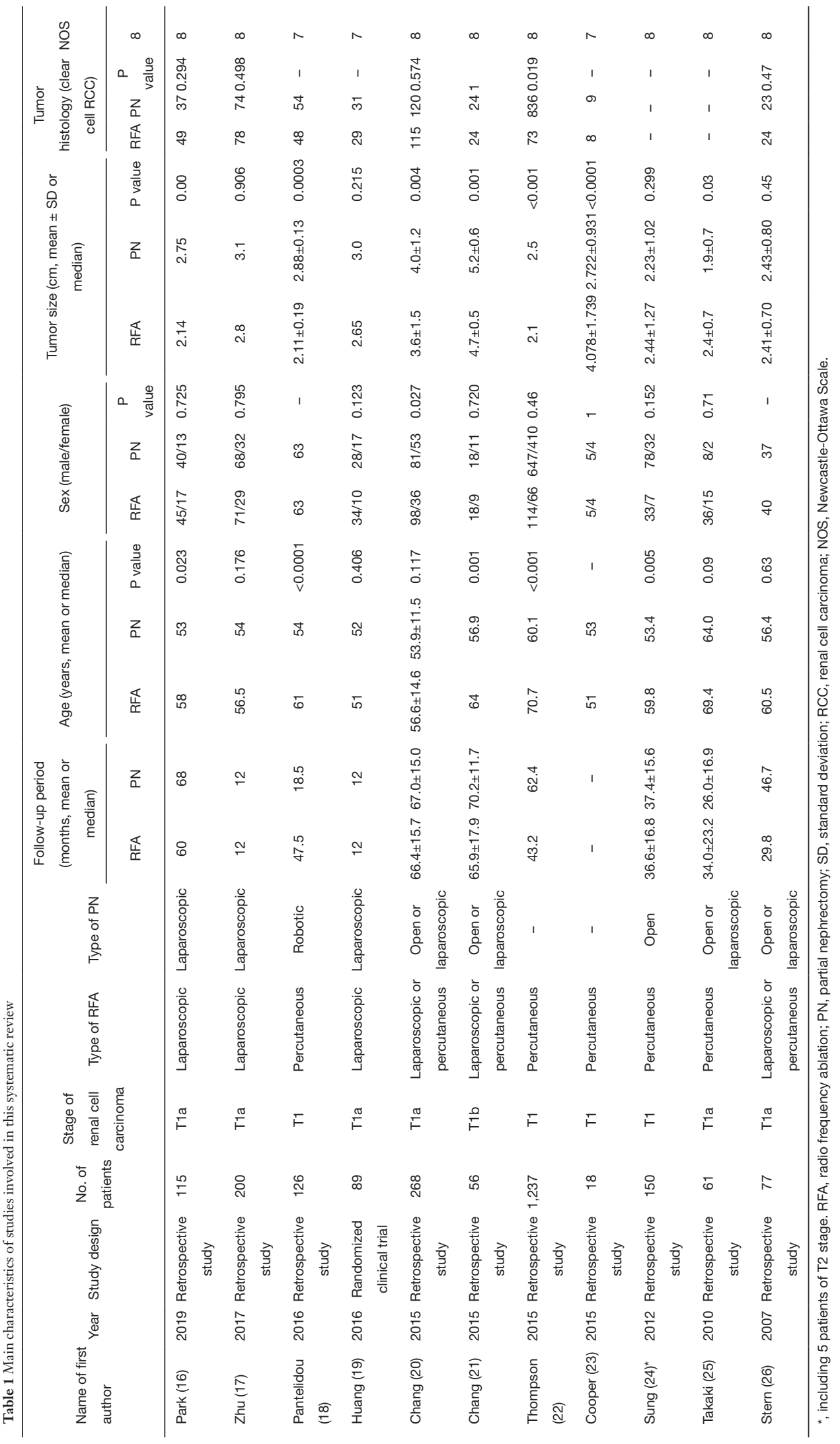


Table 2 Summary results of long-term survival between RFA and PN treatment group

\begin{tabular}{lccccc}
\hline Name of first author & Year & No. of patients & Methods & HR (PN vs. RFA) & 95\% Cl \\
\hline Chang (20) & 2015 & 90 & Overall survival rate & 1.00 & $0.81-1.24$ \\
Chang (21) & 2015 & 56 & Overall survival rate & 0.86 & $1.49-1.50$ \\
Thompson (22) & 2015 & 1,237 & Overall survival rate & $1.62-2.45$ \\
Chang (20) & 2015 & 150 & Recurrence-free survival rate & 1.02 & $0.67-1.56$ \\
Sung (24) & 2012 & 77 & Recurrence-free survival rate & 1.06 & $0.84-1.31$ \\
Stern (26) & 2007 & 90 & $0.53-2.22$ \\
\hline
\end{tabular}

RFA, radio frequency ablation; $\mathrm{PN}$, partial nephrectomy; HR, hazard ratio; $\mathrm{Cl}$, confidence interval.

Table 3 Summary results of complication events between RFA and PN treatment group

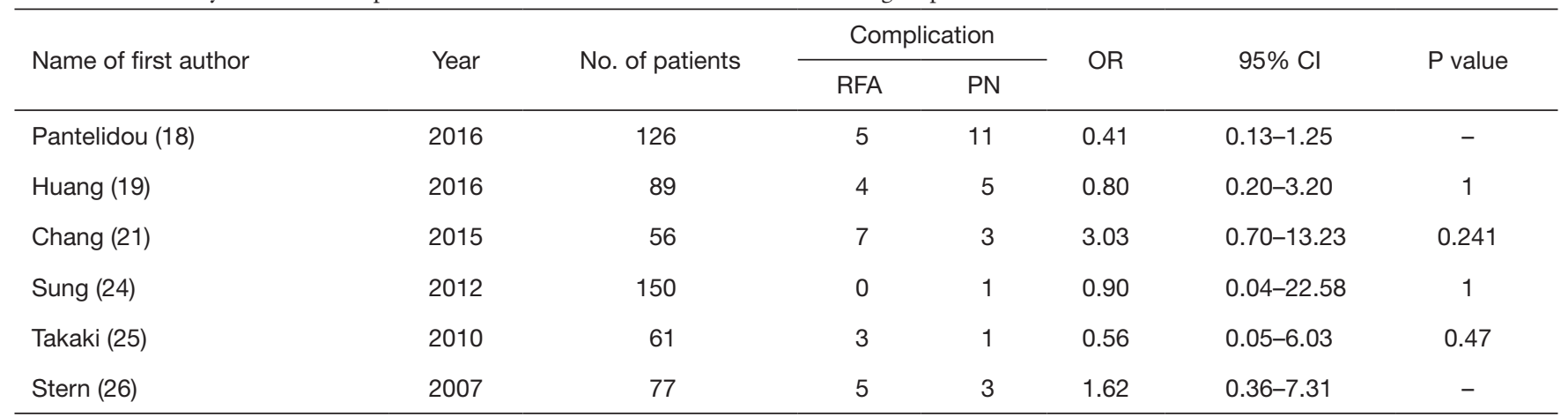

Urinary complications and bleeding were the primary complication, including urine leak, urinary retention and delay bleeding. RFA, radio frequency ablation; PN, partial nephrectomy; OR, odds ratio; $\mathrm{Cl}$, confidence interval.

Table 4 Summary results of GFR change between RFA and PN in renal tumor

\begin{tabular}{|c|c|c|c|c|c|c|c|c|c|c|c|}
\hline $\begin{array}{l}\text { Name of } \\
\text { first author }\end{array}$ & Year & $\begin{array}{c}\text { No. of } \\
\text { patients }\end{array}$ & \multicolumn{3}{|c|}{ Pre-GFR $\left(\mathrm{mL} / \mathrm{min} / 1.73 \mathrm{~m}^{2}\right)$} & \multicolumn{3}{|c|}{ Post-GFR $\left(\mathrm{mL} / \mathrm{min} / 1.73 \mathrm{~m}^{2}\right)$} & \multicolumn{3}{|c|}{ Change in GFR (mL/min/1.73 $\mathrm{m}^{2}$ or \%) } \\
\hline Park (16) & 2019 & 115 & $\begin{array}{c}94.2 \\
(35.82-193)\end{array}$ & $\begin{array}{c}97.5 \\
(30.2-155)\end{array}$ & 0.499 & $\begin{array}{c}84.3 \\
(18.4-138)\end{array}$ & $\begin{array}{c}91 \\
(41.9-133.7)\end{array}$ & 0.092 & $\begin{array}{c}9.85 \\
(-26.7 \text { to } 47.9)\end{array}$ & $\begin{array}{c}6.53 \\
(-62.8 \text { to } 90.3)\end{array}$ & 0.395 \\
\hline Zhu (17) & 2017 & 200 & $36.30 \pm 9.18$ & $38.31 \pm 8.29$ & 0.107 & $32.41 \pm 8.19$ & $31.32 \pm 7.04$ & 0.314 & $-9.41 \pm 13.82$ & $-17.13 \pm 15.19$ & $<0.001$ \\
\hline Huang (19) & 2016 & 89 & - & - & - & - & - & - & 4.5 & -11.1 & 0.048 \\
\hline Chang (20) & 2015 & 268 & $97.2 \pm 30.0$ & $105.7 \pm 27.7$ & 0.017 & $82.7 \pm 34.2$ & $78.8 \pm 29.8$ & 0.311 & -14.5 & -26.9 & - \\
\hline Chang (21) & 2015 & 56 & $78.8 \pm 28.9$ & $86.4 \pm 29.3$ & 0.318 & $71.6 \pm 25.4$ & $76.9 \pm 25.0$ & 0.437 & -7.2 & -9.5 & - \\
\hline Takaki (25) & 2010 & 61 & $\begin{array}{c}49.2 \\
(39.3-63.6)\end{array}$ & $\begin{array}{c}68.6 \\
(57.2-79.6)\end{array}$ & 0.01 & $\begin{array}{c}49.8 \\
(35.5-61.0)\end{array}$ & $\begin{array}{c}65.1 \\
(52.6-74.0)\end{array}$ & 0.02 & $\begin{array}{c}3.2 \\
(-3.6 \text { to } 8.2)\end{array}$ & $\begin{array}{c}7.0 \\
(-7.8 \text { to } 11.5)\end{array}$ & 0.34 \\
\hline
\end{tabular}

RFA, radio frequency ablation; PN, partial nephrectomy; GFR, glomerular filtration rate. 
risk of perforation, fistula and stenosis (30). They suggested that these risks can be avoided by non-ablative treatment. Therefore, the safety and long-term tumor efficacy of RFA remained controversial. Compared with individual studies, systematic reviews can provide comprehensive and reliable results and help explain controversial conclusions. For this reason, we conducted a systematic review to explore whether RFA has significant benefits for small renal tumors compared with PN.

The primary limitation of individual studies is lack of observation concerning long-term prognosis of RFA, including local recurrence rate and long-term survival rate. Our results demonstrated that RFA played a positive but similar role in long-term survival compared with PN. Nonetheless, the overall survival rate of PN group was obviously higher in Thompson's research possibly because of the selection bias (22). In their study, patients treated with $\mathrm{PN}$ were significantly younger $(\mathrm{P}<0.001)$ and had lower Charlson scores $(\mathrm{P}<0.001)$ than those treated with RFA. Furthermore, Sung et al. reported that since the ablation edge of RFA is unclear on unenhanced CT, it is difficult to determine whether the tumor edge is sufficiently ablated during RFA surgery (24). They suggested that if the surgery is performed by less experienced operators, it may result in postoperative residual and recurrence. As a result, the operator experience might have a certain impact on the recurrence-free survival of RFA.

In our study, the complication rate in RFA group was equivalent to that described in $\mathrm{PN}$ group. Urinary complications and bleeding were the primary complications of RFA. The goal of RFA is to induce temperatures between 50 and $100{ }^{\circ} \mathrm{C}$ throughout the tumor tissue. Irreversible cell damage resulting from high temperatures in RFA treatment may lead to the injury of urinary tract, microvasculature and arterioles, causing the above-mentioned complications. Previous studies revealed that the use of renal pelvis perfusion might reduce the risk of ureteral injury (31). Nevertheless, it might cause inadvertent damage to nerves simultaneously.

It is well known that renal function preservation is another important goal for patients with small renal tumors. Our results indicated that most patients had a smaller decline in renal function after RFA compared with PN method (17-19,24), while another three studies concluded that RFA had a similar benefit as $\mathrm{PN}$ in renal function preservation $(16,23,25)$. In these three studies, the mean tumour size $(2.14$, $4.078,2.4 \mathrm{~cm})$ treated by RFA were significantly larger than those $(2.75,2.722,1.9 \mathrm{~cm})$ treated by PN. The researchers failed to match for tumour size in their study. As mentioned previously, tumor size was regarded as a significant indicator of the outcomes of patients with RFA. Therefore, lack of matching tumor size may reduce the accuracy of the results to a certain extent. Furthermore, retained renal parenchyma and warm-ischemia time (WIT) play important roles in affecting postoperative renal function (32). Krokidis et al. (33) revealed that RFA did not require clamping the main renal artery, thus eliminating the WIT required for all types of surgical removal of the kidney mass. Therefore, RFA therapy might be superior to $\mathrm{PN}$ in preserving renal function.

Admittedly, there are still several limitations in our review. First, we only enrolled 11 articles which focused on the outcomes between RFA and PN in T1 renal tumors. With an increasing number of clinical studies being published, more high-quality studies could be enrolled to strength our conclusion. Second, our systematic review was composed of 11 individual articles with different contents, which might result in limited statistical validity and scattered results. Third, other information besides tumor size and histology (e.g., tumor location and ethnicity) was not available in most studies. Fourth, Sung's study (24) included five RCC patients of stage T2, which might cause a slight bias. However, due to limited number of studies comparing these two methods, they were also included in this analysis. More studies with high-quality are required in the future to get more accurate results.

In conclusion, RFA is an effective treatment option which requires enough training and sufficient experience. Despite of its postoperative complications, the advantages of RFA are evident. For patients with T1 renal tumors, it could provide comparable long-term oncologic outcomes to $\mathrm{PN}$ and promote renal function preservation. Nevertheless, further studies are required to draw a more accurate conclusion.

\section{Acknowledgments}

Funding: This work was supported by grants from the National Natural Science Foundation of China (No. 81702520), Medical Research Project of Jiangsu Provincial Health and Family Planning Commission (No. H2018052), Research Project of Jiangsu Cancer Hospital (No. ZN201602), and the young talents program of Jiangsu Cancer Hospital (No. 2017YQL-04).

\section{Footnote}

Conflicts of Interest: The authors have no conflicts of interest to declare. 
Ethical Statement: The authors are accountable for all aspects of the work in ensuring that questions related to the accuracy or integrity of any part of the work are appropriately investigated and resolved.

\section{References}

1. Rini BI, Campbell SC, Escudier B. Renal cell carcinoma. Lancet 2009;373:1119-32.

2. Siegel R, Naishadham D, Jemal A. Cancer statistics. CA Cancer J Clin 2013;63:11-30.

3. Zagoria RJ. Imaging of small renal masses: a medical success story. AJR Am J Roentgenol 2000;175:945-55.

4. Farber NJ, Kim CJ, Modi PK, et al. Renal cell carcinoma: the search for a reliable biomarker. Transl Cancer Res 2017;6:620-32.

5. Reddan DN, Raj GV, Polascik TJ. Management of small renal tumors: an overview. Am J Med 2001;110:558-62.

6. Kassouf W, Aprikian AG, Laplante M, et al. Natural history of renal masses followed expectantly. J Urol 2004;171:111-3.

7. Fergany AF, Hafez KS, Novick AC. Long-term results of nephron sparing surgery for localized renal cell carcinoma: 10-year follow-up. J Urol 2000;163:442-5.

8. Van Poppel H, Da Pozzo L, Albrecht W, et al. A prospective, randomised EORTC intergroup phase 3 study comparing the oncologic outcome of elective nephronsparing surgery and radical nephrectomy for low-stage renal cell carcinoma. Eur Urol 2011;59:543-52.

9. Gratzke C, Seitz M, Bayrle F, et al. Quality of life and perioperative outcomes after retroperitoneoscopic radical nephrectomy ( $\mathrm{RN}$ ), open $\mathrm{RN}$ and nephron-sparing surgery in patients with renal cell carcinoma. BJU Int 2009;104:470-5.

10. Shah DR, Green S, Elliot A, et al. Current oncologic applications of radiofrequency ablation therapies. World J Gastrointest Oncol 2013;5:71-80.

11. Whitson JM, Harris CR, Meng MV. Population-based comparative effectiveness of nephron-sparing surgery vs ablation for small renal masses. BJU Int 2012;110:1438-43; discussion 1443.

12. Kang DC, Palmer DA, Zarei M, et al. A systematic review of the quality of evidence of ablative therapy for small renal masses. J Urol 2012;187:44-7.

13. Kunkle DA, Egleston BL, Uzzo RG. Excise, ablate or observe: the small renal mass dilemma-a meta-analysis and review. J Urol 2008;179:1227-33; discussion 1233-4.

14. Pan XW, Cui XM, Huang H, et al. Radiofrequency ablation versus partial nephrectomy for treatment of renal masses: A systematic review and meta-analysis. Kaohsiung J Med Sci 2015;31:649-58.

15. Moher D, Liberati A, Tetzlaff J, et al. Preferred reporting items for systematic reviews and meta-analyses: the PRISMA statement. Int J Surg 2010;8:336-41.

16. Park JM, Yang SW, Shin JH, et al. Oncological and Functional Outcomes of Laparoscopic Radio frequency Ablation and Partial Nephrectomy for T1a Renal Masses: A Retrospective Single-center 60 Month Follow-up Cohort Study. Urol J 2019;16:44-9.

17. Zhu L, Wu G, Huang J, et al. Comparing renal function preservation after laparoscopic radio frequency ablation assisted tumor enucleation and laparoscopic partial nephrectomy for clinical T1a renal tumor: using a 3D parenchyma measurement system. J Cancer Res Clin Oncol 2017;143:905-12.

18. Pantelidou M, Challacombe B, McGrath A, et al. Percutaneous Radiofrequency Ablation Versus RoboticAssisted Partial Nephrectomy for the Treatment of Small Renal Cell Carcinoma. Cardiovasc Intervent Radiol 2016;39:1595-603.

19. Huang J, Zhang J, Wang Y, et al. Comparing Zero Ischemia Laparoscopic Radio Frequency Ablation Assisted Tumor Enucleation and Laparoscopic Partial Nephrectomy for Clinical T1a Renal Tumor: A Randomized Clinical Trial. J Urol 2016;195:1677-83.

20. Chang X, Liu T, Zhang F, et al. Radiofrequency ablation versus partial nephrectomy for clinical T1a renal-cell carcinoma: long-term clinical and oncologic outcomes based on a propensity score analysis. J Endourol 2015;29:518-25.

21. Chang X, Zhang F, Liu T, et al. Radio frequency ablation versus partial nephrectomy for clinical $\mathrm{T} 1 \mathrm{~b}$ renal cell carcinoma: long-term clinical and oncologic outcomes. J Urol 2015;193:430-5.

22. Thompson RH, Atwell T, Schmit G, et al. Comparison of partial nephrectomy and percutaneous ablation for cT1 renal masses. Eur Urol 2015;67:252-9.

23. Cooper CJ, Teleb M, Dwivedi A, et al. Comparative Outcome of Computed Tomography-guided Percutaneous Radiofrequency Ablation, Partial Nephrectomy or Radical Nephrectomy in the Treatment of Stage T1 Renal Cell Carcinoma. Rare Tumors 2015;7:5583.

24. Sung HH, Park BK, Kim CK, et al. Comparison of percutaneous radiofrequency ablation and open partial nephrectomy for the treatment of size- and locationmatched renal masses. Int J Hyperthermia 2012;28:227-34. 
25. Takaki H, Yamakado K, Soga N, et al. Midterm results of radiofrequency ablation versus nephrectomy for T1a renal cell carcinoma. Jpn J Radiol 2010;28:460-8.

26. Stern JM, Svatek R, Park S, et al. Intermediate comparison of partial nephrectomy and radiofrequency ablation for clinical T1a renal tumours. BJU Int 2007;100:287-90.

27. Klatte T, Shariat SF, Remzi M. Systematic review and meta-analysis of perioperative and oncologic outcomes of laparoscopic cryoablation versus laparoscopic partial nephrectomy for the treatment of small renal tumors. J Urol 2014;191:1209-17.

28. Liang P, Wang Y, Zhang D, et al. Ultrasound guided percutaneous microwave ablation for small renal cancer: initial experience. J Urol 2008;180:844-8; discussion 848.

29. Dominguez-Escrig JL, Sahadevan K, Johnson P.

Cite this article as: Wei X, Ren X, Ding Y, Wang H, Li Y, Li X, Gao Y. Comparative outcomes of radio frequency ablation versus partial nephrectomy for T1 renal tumors: a systematic review. Transl Androl Urol 2019;8(6):601-608. doi: $10.21037 /$ tau.2019.10.13
Cryoablation for small renal masses. Adv Urol 2008:479495.

30. Wah TM, Irving HC, Gregory W, et al. Radiofrequency ablation (RFA) of renal cell carcinoma (RCC): experience in 200 tumours. BJU Int 2014;113:416-28.

31. McCarthy CJ, Gervais DA. Decision Making: Thermal Ablation Options for Small Renal Masses. Semin Intervent Radiol 2017;34:167-75.

32. Volpe A, Blute ML, Ficarra V, et al. Renal ischemia and function after partial nephrectomy: a collaborative review of the literature. Eur Urol 2015;68:61-74.

33. Krokidis ME, Kitrou P, Spiliopoulos S, et al. Imageguided minimally invasive treatment for small renal cell carcinoma. Insights Imaging 2018;9:385-90. 